\title{
MÖSSBAUER SPECTROSCOPY OF IRON-CONTAINING DERMAL GRANULES FROM MOLPADIA INTERMEDIA
}

\author{
S. OFER ${ }^{a} *$, G.C. PAPALI"THYMIOU ${ }^{a}$, R.B. FRANKEL ${ }^{a}$ and H.A. LOWENSTAM ${ }^{b}$ \\ ${ }^{a}$ Francis Bitter National Magnet Laboratory, Massachuserts Institute of Technology, Cambridge, MA 02139 and ${ }^{\mathrm{b}}$ Department o \\ Geological and Planetary Sciences, California Institute of Technology. Pasadena, CA 91125 (U.S.A.)
}

Key words: Iron deposition; Dernal granule; Mössbatuer spectroscopy; (Molpadia intermedia)

Dermal granules containing hydrous ferric oxide cores from Molpadia intermedia were studied by Mössbauer spectroscopy from 1.5 to $300 \mathrm{~K}$ and in magnetic fields up to $80 \mathrm{kOersted}$ at $4.2 \mathrm{~K}$. A magnetic phase transition to an antiferromagnetically ordered state is observed at $10 \mathrm{~K}$. The results are compared with the magnetic behavior of micellar cores of ferritin from eukaryotes and iron-storage materials from prokaryotes.

In acldition to the utijization of iron atoms in proteins for oxygen and electron transport and other metabolic purposes, many organisms sequester iron in the form of hydrous ferric oxides [1]. The most widely studied biomineralization product of this type occurs in the iron storage protein ferritin, where is forms a $70 \AA$ micellar core of approximate composition $(\mathrm{FeOOH})_{8} \cdot \mathrm{FeO} \cdot \mathrm{OPO}_{3} \mathrm{H}_{2}[2,3]$ or $2.5 \mathrm{Fe}_{2} \mathrm{O}_{3}$ $4.5 \mathrm{H}_{2} \mathrm{O}[1,4]$ surrounded by a polypeptide sheath. Micelles of similar composition occur in the related iron-storage material hemosiderin [5] and in bacterioferritin from Azotobacter vinelandii [6]. Magnetite $\left(\mathrm{Fe}_{3} \mathrm{O}_{4}\right)$ is the most common of the known iron oxide biominerals [7]. It occurs in chitons [8-10], magnetotactic bacteria [11] and a variety of other organisms [12]. Ferritin forms the precursor mineral of magnetite in chitons $[9,12]$. A storage material witl a Mössbauer spectrum similar to that of ferritin is observed in magnetotactic bacteria [11]. Another iron-rich storage material of as yet unknown composition has been observed in prokaryotic cells grown in iron-rich media [13-15].

Molpadia intermedia (Holothuroidea) is a species of marine invertebrates commonly known as sea

\footnotetext{
* Present address: Racah Institute of Plysics, Hebrew University, Jerusalem, Isracl.
}

cucumber. Starting at the late juvenile stage, these organisms synthesize iron- and phosphate-rich dermal granules ranging in size from 10 to $350 \mu \mathrm{m}$ which serve as strengthening agents in the connective tissues of their dermis [16]. The microarchitecture and mineralogic composition of the granules have been studied by a variety of physical and chemical techniques [17]. They consist of layers composed of two types of spherical to ellipsoidal subunits, 0.03-0.24 $\mu \mathrm{m}$ in diameter, separated and alternately encapsulated by organic material. One type of subunit contains water, iron and phosphate, with lesser amounts of calcium and magnesium. These deposits are X-ray amorphous and in turn consist of electron-dense subunits $90-140 \AA$ in diameter. The iron is present in the form of hydrous ferric polymeric units similar to the iron-containing micelles of ferritin.

Because the iron-containing granular cores from Molpadia are a structurally and chemically well characterized biomineralization product, it is interesting to investigate their magnetic properties for comparison with the iron micelles of ferritin and with the other ion-storage materials from prokaryotic cells, as well as with the precursors to magnetite formation in magnetotactic bacteria and chitons. Therefore, we have made Mössbauer spectroscopic measurements on the isolated dermal granules from 1.5 to $300 \mathrm{~K}$ 
and in an external magnetic field of $80 \mathrm{kOersted}$ at $4.2 \mathrm{~K}$.

\section{Experimental Procedure}

Granules were extracted from the dermal tissues of $M$. intermedia s.1. as described by Lowenstam and Rossman [17]. Mössbauer measurements were made using a conventional, constant-acceleration spectrometer.with a source of ${ }^{57} \mathrm{Co}$ in rhodium, which was maintained at room temperature. The sample was mounted on a copper block inside a Janis Veritemp Dewar and temperatures between 1.5 and $300 \mathrm{~K}$ were maintained and measured with a calibrated silicon diode and a Lake Shore Cryotronics Temperature Controller. The spectra were least-squares fitted by a program developed by J. Teillet and F. Varret (personal communication) to generate theoretical Mössbauer spectra with Lorentzian lineshapes in order to yield isomer shifts, quadrupole splittings, internal magnetic fields, linewidtlis and line intensities.

Spectra of Molpadia dermal granules were obtained between 1.5 and $300 \mathrm{~K}$ and in a longitudinal magnetic field of 80 kOersted at $4.2 \mathrm{~K}$. Spectra of lyophilized horse spleen ferritin and lyophilized ironstorage material from Escherichia coli prepared as previously reported [13] were also obtained at several temperatures between 4.2 and $300 \mathrm{~K}$.

\section{Results}

The spectrum of Molpadia dermal granules at temperatures between 10 and $300 \mathrm{~K}$ is a broadened quadrupole doublet with an average linewidth $\Gamma=$ $0.55 \pm 0.02 \mathrm{~mm} / \mathrm{s}$, indicating a distribution of electric-field gradients at the iron sites. Satisfactory fits were obtained with two overlapping quadrupole doublets simulating the distribution in the electricfield gradients. The weighted averages of the Mössbauer parameters at various temperatures are listed in Table $\mathrm{J}$. Below $10 \mathrm{~K}$ the spectrum broadens and magnetic hyperfine structure appears, with the effective magnetic field at the nucleus increasing with decreasing temperature (Fig. 1). The breadth of the outer lines compared to the inner lines in Fig. 10 indicates a distribution of magnetic hyperfine fields. The magnetically split spectra were fitted by assum.
TABLE I.

\section{MÖSSBAUER PARAMETERS}

Weighted averages of the two superiniposed subspectr least-square fits are presented. Isomer shifts $(\delta)$ are rel metallic iron at soom temperature.

\begin{tabular}{ccll}
\hline Compound & $T(\mathrm{~K})$ & $\delta(\mathrm{nm} / \mathrm{s})$ & $\Delta E_{\mathrm{Q}}$ \\
\hline Molpadia & 10.4 & $0.51 \pm 0.02$ & $0.86 \pm$ \\
dermal & 20 & 0.50 & 0.83 \\
granules & 130 & 0.48 & 0.84 \\
& 150 & 0.46 & 0.83 \\
& 200 & 0.44 & 0.81 \\
& 250 & 0.41 & 0.80 \\
& 300 & 0.39 & 0.83 \\
E. coli & 45 & 0.52 & 0.68 \\
storage & 150 & 0.50 & 0.66 \\
material & 200 & 0.46 & 0.66 \\
& 250 & 0.44 & 0.65 \\
Ferritil & 300 & 0.41 & 0.64 \\
& 130 & 0.47 & 0.73 \\
& 200 & 0.42 & 0.77 \\
Amorphous & 250 & 0.40 & 0.77 \\
ferric gel & 77 & $0.47 \mathrm{a}, \mathrm{b}$ & $0.81 \mathrm{a}$ \\
\hline
\end{tabular}

a Ref. 18

b $0.62 \mathrm{~mm} / \mathrm{s}$ quoted relative to Cr source in Ref. 18 .

ing 30 overlapping subspectra with different mi hyerpfine ficlds between 0 and $500 \mathrm{kOerstec}$ relative intensities as free parameters. The sm results of these fits at several temperatures a sented in Fig. 2, where relative intensity is plo a function of effective magnetic field at the $n$ At $1.6 \mathrm{~K}$, the mode of the distribution is : kOersted and moves to progressively lower fielc increasing temperature, collapsing at about 10 quadrupole doublet and the magnetically spli tra coexist from approx. 8.0 to $10.0 \mathrm{~K}$. The I intensity of the quadrupole doublet is given

2. The collapse of the magnetic hyperfine sp? is indicative of a magnetic transition at about with a distribution of transition temperatures sample from 8.0 to $10.0 \mathrm{~K}$.

The spectrum obtained in a longitudinal $\mathrm{mc}$ field at 80 kOersted at $4.2 \mathrm{~K}$ is shown in Fig. 3 effect of the applied field is to broaden the without substantially changing the line positi 


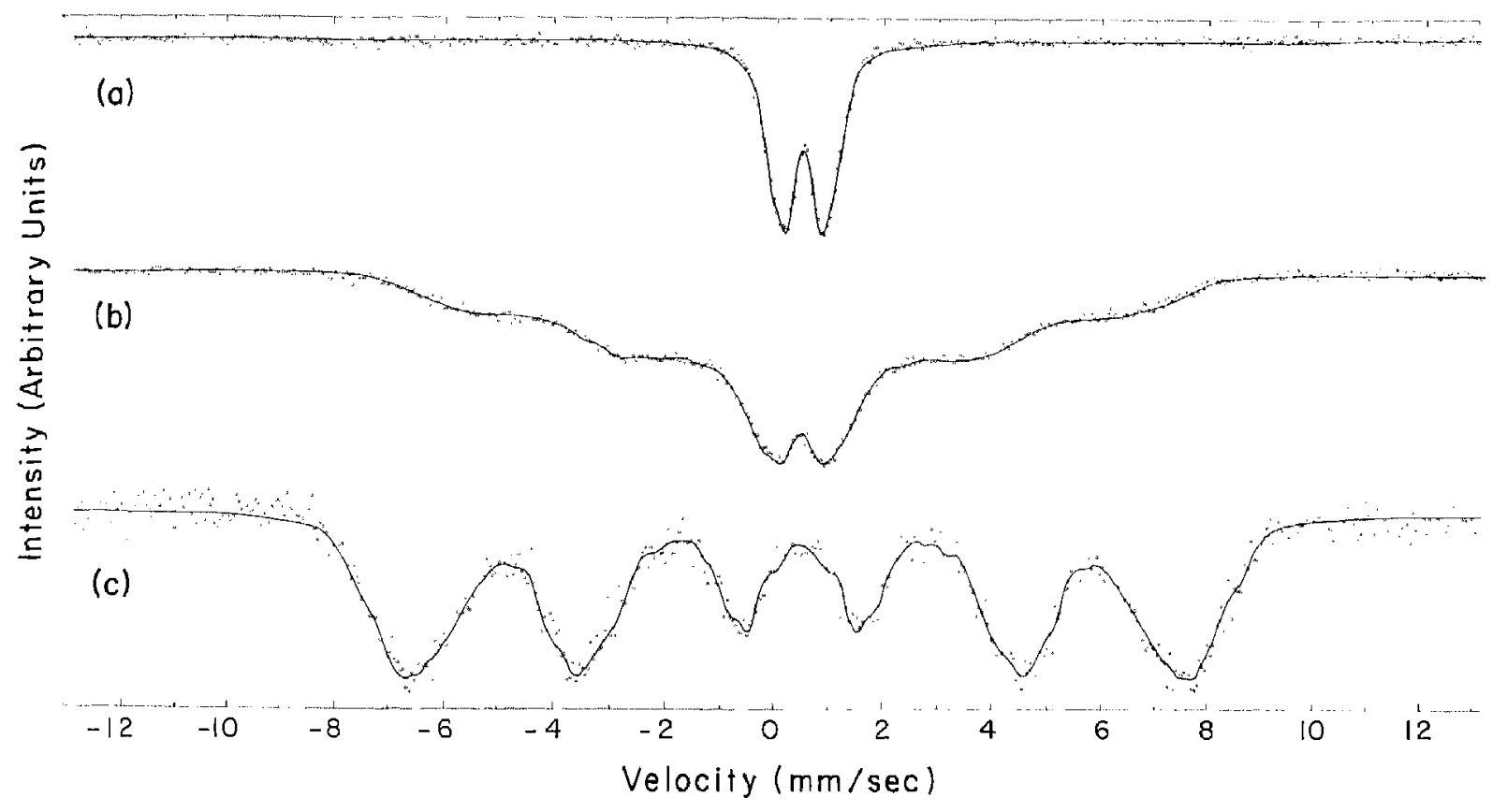

Fig. 1. Mössbauer spectra of Molpadia dermal granules at (a) $T=20 \mathrm{~K}$, (b) $T=7.2 \mathrm{~K}$ and (c) $T=1.6 \mathrm{~K}$.

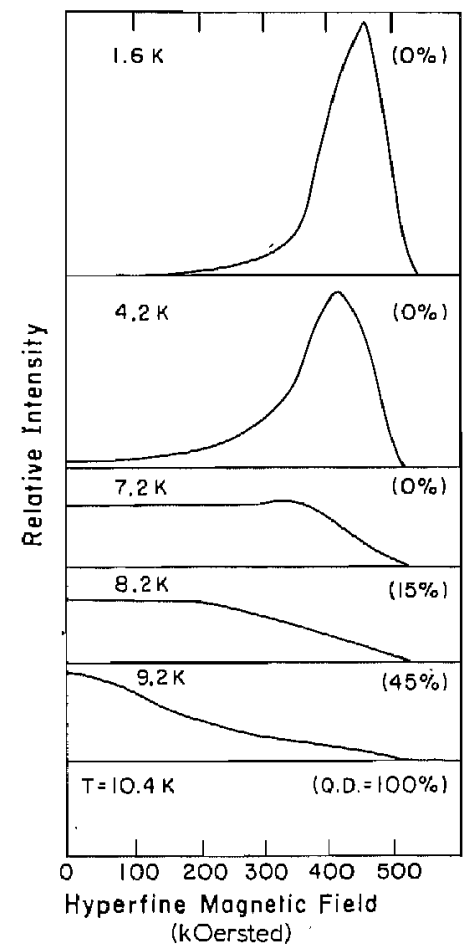

Fig. 2. Distribution of magnetic hyperfine fields at the iron nucleus in Molpadia dermal granules at different temperatures obtained from least-squares fits of the Mössbauer spectra. The numbers in parentheses give the percentage of absorption area under the central quadrupole doublet (Q.D.).

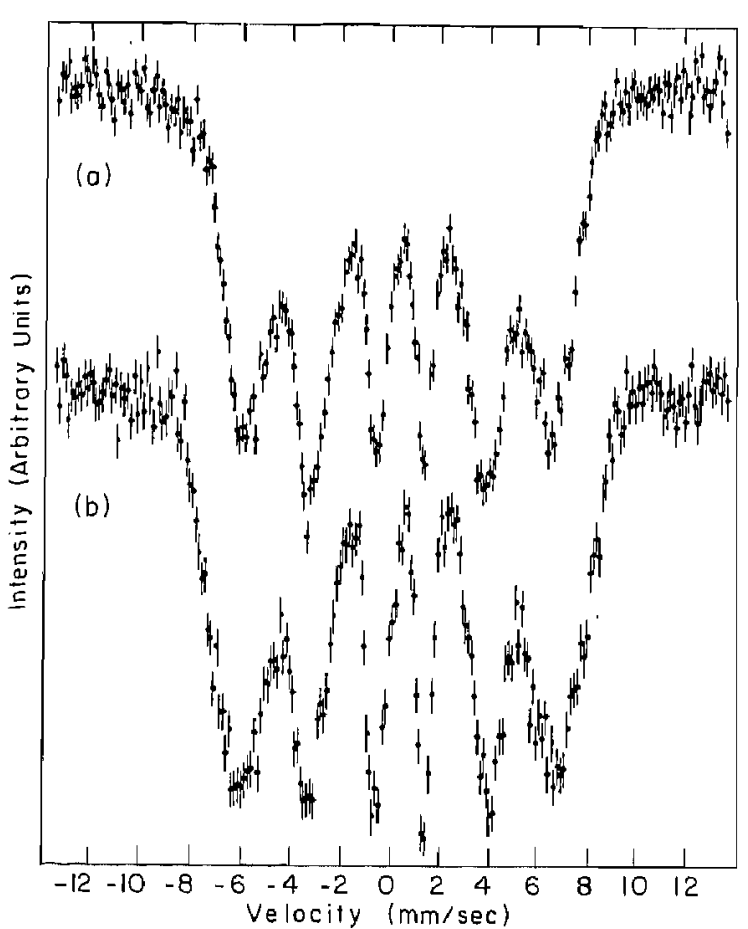

Fig. 3. Mössbauer spectra of Molpadia dermal granules at $T=$ $4.2 \mathrm{~K}$ : (a) in zero field and (b) in an applied field, $H=80$ kOersted parallel to the $\gamma$-ray direction. 


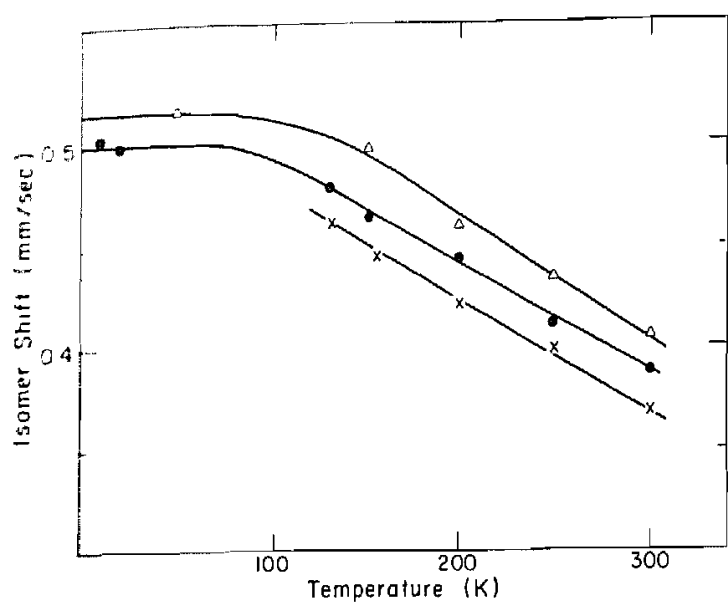

Fig. 4. Isomer shifts (relative to metallic iron) for Molpadia dermal granules $(\bullet), E$. coli storage materials $(\Delta)$, and ferritin $(X)$ as a function of temperature.

relative intensities compared to zero field (Fig. 3a). This result is expected for a randomly oriented powder sanıple in which the spins are coupled antiferromagnetically of speromagnetically [18], with anisotropy fields $H_{\mathrm{A}} \gg 80$ kOersted.

Spectra for horse spleen ferritin and $E$. coli storage material were similar to previously reported spectra in Refs. 19, 20 and 13, respectively. Computer fits were obtained assuming two overlapping quadrupole doublets in each case. Representative data are pre-

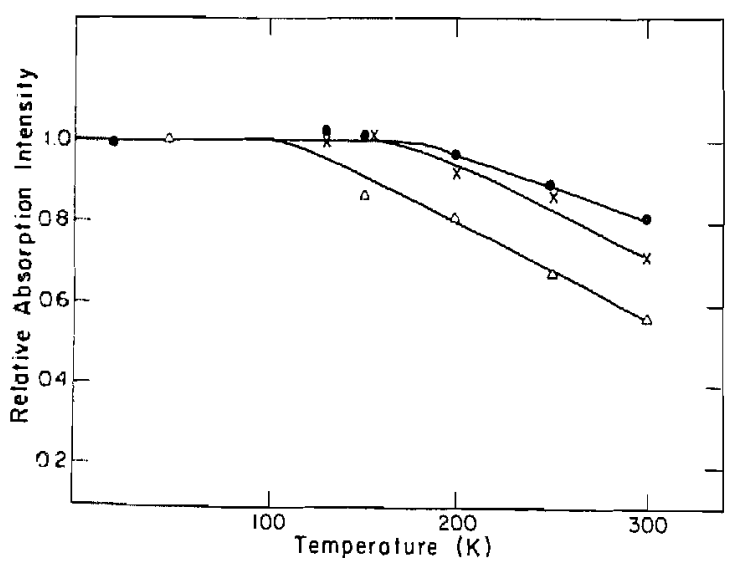

Fig. 5. Relativc absorption intensity of the Mössbauer spectrum for Molpadia dermal granules ( $), E$. coli storage protein $(A)$ and ferritin $(X)$ as a function of temperature. sented in Table $\mathrm{I}$. Isomer shifts and relative intensitie obtained from the fits are plotted in Fig. 4 and 5 Again, only the weighted averages of the Mössbaue parameters of the two superimposed subspectra art presented. Also presented in Table I are parameter for a naturally occuring amorphous ferric gel 0 approximate composition $\mathrm{Fe}(\mathrm{OH})_{3} \cdot 0.9 \mathrm{H}_{2} \mathrm{O}$ [18].

\section{Discussion}

The Molpadia spectra can be interpreted in term: of a transition from a paramagnetic state to a magnet ically ordered state below $10 \mathrm{~K}$. The distribution 0 transition temperatures below $10 \mathrm{~K}$ in the sample a: well as the distribution of hyperfine fields in the ordered state are consistent with the amorphou: nature of the iron-containing subunits, as determine by X-ray analysis [17]. In an amorphous structure the iron-iron distances and the density of iron atom: might be expected to vary, giving rise to a distribu tion of the Néel temperatures and hyperfine fields However, spectra with a superposition of magneti cally split and paramagnetic components near the Néel temperature have also been obtained in wel crystallized $\gamma$-FeOOH [21].

The high-temperature spectra of the iron-ricl cores of Molpadia dermal granules, ferritin anc $E$. coli storage material are very similar, but thert are experimentally distinguishable differences in the quadrupole splittings and isomer shifts. The observer quadrupole splittings for Molpadia are on the averagt about $10 \%$ higher than those observed for ferritin anc about $20 \%$ higher than those of E. coli storage pro tein (Table I). The isomer slifts of the various mate rials are similar to the Molpadia values, falling between those of $E$. coli and ferritin (Fig, 3). Thi major differences, however, are in the temperaturs dependence of the respective spectra. The Mössbaue spectrum of ferritin and its insoluble analogue hemo siderin shows a temperature dependence characteris tic of superparamagnetic behavior of magnetically ordered fine particles $[19,20]$. That is, although the iron core is antiferromagnetically ordered below about $200 \mathrm{~K}$ [19], thermally activated transitions between equivalent easy axes motionally narrow the magnetic hyperfine spectrum to a quadrupole double when the transition rate exceeds the Larmor preces sion time. Thus, the high-temperature spectrum ( $T$ > 
$50 \mathrm{~K}$ ) is a broadened quadrupole doublet, with isomer shift and quadrupole splitting characteristic of high-spin $\mathrm{Fe}^{3+}$. The low-temperature spectrum $(T<$ $10 \mathrm{~K}$ ) is a magnetic hyperfine sextet with a well defined magnetic splitting of 497 kOersted independent of temperature. As the transition rate is an exponential function of the temperature, magnetic anisotropy and volume of the micelles [22], a distribution of micellular diameters about the $70 \AA$ mean results in a coexistence of quadrupole and magnetic liyperfine spectra for $10<T<50 \mathrm{~K}$, with the relative intensity of the high-temperature spectrum increasing with increasing temperature. The splitting of the low-temperature spectrum is also independent of temperature in this temperature range $(10 \mathrm{~K}<T<$ $50 \mathrm{~K})$. Similar spectra with a low-temperature magnetic splitting of $458 \mathrm{kOersted}$ and a coexistence region $10<T<20 \mathrm{~K}$ are observed for the amorphous ferric gel presented in Table I [18].

The Mössbauer spectrum for $T>10 \mathrm{~K}$ of the ironstorage material from $E$. coli [13] and the other prokaryotes Proteus mirabilis [15], and Mycoplasma capricolumn [14], is a quadrupole doublet with parameters characteristic of high-spin $\mathrm{Fe}^{3+}$. A six-line magnetic hyperfine spectrum with an effective magnetic field at the nucleus of $430 \mathrm{kOersted}$ is observed at $T<1 \mathrm{~K}$. Above $1 \mathrm{~K}$ the lines broaden and the splitting decreases with increasing $T$ and collapses into the quadrupole doublet at about $3.5 \mathrm{~K}$. Between 1.2 and $3.5 \mathrm{~K}$ the doublet and sextet are superposed, inclicating a spread of magnetic transition temperatures.

The low-temperature magnetic behavior of the Molpadia dernal granules as observed via Mössbauer spectroscopy is more similar to that of the prokaryotic iron-storage materials than to ferritin. Firstly, there is a low-temperature $\left(T_{\mathrm{c}} \approx 10 \mathrm{~K}\right) \mathrm{mag}$ netic transition with a distribution of transition temperatures $\left(\Delta T_{\mathrm{c}} \approx 2 \mathrm{~K}\right)$. In the prokaryotic storage materials the magnetic transition occurs at about $3 \mathrm{~K}$, whereas in ferritin the magnetic transition occurs at approx. $200 \mathrm{~K}$ [19]. Secondly, there is a distribution of saturation hyperfine fields that peaks at 440 kOersted. In the prokaryotic storage material the saturation hyperfine fields peak at 430 kOersted [13], whereas in ferritin the saturation hyperfine field distribution peaks at $497 \mathrm{kOersted}$ [19].

These differences may reflect different biological functions of the materials. Iron storage in ferritin is reversible and $\mathrm{Fe}$ ions can be extracted from the micelles in response to metabolic demands for iron. This reversible storage may require a high degree of structural order in micelles [23]. Heald et al. [3] have proposed a model in which the Fe ions are bound in planar sheets, with the sheets relatively well separated from each other and terminated by $\mathrm{H}_{2} \mathrm{PO}_{3}$. By con. trast, iron storage in the dermal granules of Molpadia appears to be largely a final biological product and in the main is presumably not remobilized. Here, the hydrous iron oxide core is X-ray amorphous [17] and has a considerably higher concentration of $\mathrm{PO}_{3}$ relative to $\mathrm{Fe}$ than in ferritin. In this material the iron atoms may be further apart on the average with a consequent reduction in the magnetic ordering temperature. If the magnetic properties are indicative of biological function, this would suggest that the prokaryotic ion-storage material [13] is a final product and not a reversible iron-storage location.

\section{Acknowledgements}

We are grateful to Dr. J. Teillet for instructing us in the use of the Mössbauer line-theory program. The Francis Bitter National Magnet Laboratory is supported by the National Science Foundation. This work was partially supported by the Office of Naval Research.

\section{References}

1 Towe, K.M. and Bradley, W.F. (1967) J. Colloid Interface Sci. 24, 384-392

2 Harrison, P.M., Hoare, R.J., Hoy, T.G. and Macara, I.G. (1974) in Iron in Biochemistry and Medicine (Jacobs, A. and Worwood, M., eds.), pp. 73-114, Academic Press, New York

3 Heald, S.M., Stern, E.A., Bunker, B., Hold, E.M. and Holt, S.L. (1979) J. Am. Chem. Soc. 101, 67-73

4 Chukrov, F.V., Zvyagin, B.B., Gorshkov, A.I., Yermilova, L.P. and Balashova, V.V. (1974) Int. Geol. Rev. 16, $1131-1143$

5 Fischbach, F.G., Gregory, D.W., Harrison, P.M., Hoy, T.G. and Williams, J.M. (1974) J. Ultrastruct. Res. 37, 495-503

6 Stiefel, E.I. and Watt, G.D. (1979) Nature 279, 81-83

7 Lowenstam, H.A. (1980) in Biogeochemistry of Amino Acids (Hare, P., ed.), pp. 3-16, J. Wiley and Sons, New York

8 Lowenstam, H.A. (1962) Bull. Geol. Soc. Am. 73, 435 
9 Towe, K.M., Lowenstam, H.A. and Nesson, M.H. (1963) Science $142,63-64$

10 Towe, K.M. and Lowenstam, H.A. (1967) J. Ultrastruct. Res. 17, 1-3

11 Frankel, R.B., Blakemore, R.P. and Wolfe, R.S. (1979) Science 203, 1355-1356

12 Kirschvink, J.L. and Lowenstan, H.A. (1979) Earth Planet. Sci. Lett. 44, 193-204

13 Bauminger, E.R., Cohen, S.G., Dickson, D.P.E., Levy, A., Ofer, S., Kessel, M. and Rottem, S. (1980) Biochim. Biophys. Acta $623,237-242$

14 Bauminger, E.R., Cohen, S.G., Labenski, de Kanter, F., Levy, A., Ofer, S., Kessel, M. and Rottem, S. (1980) J. Bacteriol. 141, 378-381

I5 Dickson, D.P.E, and Rottem, S. (1979) Eur. J. Biochem. $101,291-295$
16 Clark, H.L. (1907) Smithson. Contr 17 Lowenstam, H.A. and Rossman, Geol. 15, 15-51

18 Coey, J.M.D. and Readman, P.W. Sci. Lett. 21, 45-51

19 Blaise, A., Chappert, J. and Giradet, Sci. 261, 2310 2313

20 Boas, J.F. and Window, B. (1966 $573-576$

21 Johnson, C.E. (1969) J. Phys. C 2, 1

22 Kündig, W, Bömmel, H., Constaba R.H. (1966) Phys. Rev. 142, 327-3:

23 Hoy, T.G., Harrison, P.M. and Sha chem. J. 139, 603-607 